\title{
Approaches to Training Practitioners in the Art and Science of Plant Disease Diagnosis
}

Terry M. Stewart, Institute of Natural Resources, Massey University, Palmerston North, New Zealand; and Victor J. Galea, School of Agronomy and Horticulture, University of Queensland, Gatton, Australia

\section{ABSTRACT}

Stewart, T. M., and Galea, V. J. 2006. Approaches to training practitioners in the art and science of plant disease diagnosis. Plant Dis. 90:539-547.

Allowing plant pathology students to tackle fictitious or real crop problems during the course of their formal training not only teaches them the diagnostic process, but also provides for a better understanding of disease etiology. Such a problem-solving approach can also engage, motivate, and enthuse students about plant pathology in general. This paper presents examples of three problem-based approaches to diagnostic training utilizing freely available software. The first provides an "adventure-game" simulation where students are asked to provide a diagnosis and recommendation after exploring a hypothetical scenario or "case". Guidance is given on how to create these scenarios. The second approach involves students creating their own scenarios. The third uses a diagnostic template combined with reporting software to both guide and capture students' results and reflections during a real diagnostic assignment.

Additional keywords: CHALLENGE FRAP, DIAGNOSIS FOR CROP PROBLEMS, problembased learning, scenario-based training, training software

It has been said by some that the art and science of plant disease diagnosis as defined by Grogan (4) is fast becoming a lost art, at least in English-speaking western countries where the number of field pathologists and diagnostic services has declined in recent years $(6,7,12,16,23)$. Extension pathology (of which diagnosis is a core function) has traditionally been service- rather than product-oriented, and has been a target of budget cuts, reorganization, rationalization, and privatization. The benefits of extension pathology, which serve not only the grower but wider society as a whole, are not easily assigned a monetary value. It is hard to apply a profitable business model to the activity.

Much of the diagnostic work carried out today is done by government, university, or privately owned plant clinics. These clinics may undertake field visits, but more often than not they rely on submitted plant specimens. In the absence of a field visit, the diagnostician relies on information gleaned from the specimen and perhaps from a telephone conversation, e-mail, or

Corresponding author: T. M. Stewart

E-mail: t.stewart@massey.ac.nz

Accepted for publication 27 November 2005.

DOI: 10.1094/PD-90-0539

(C) 2006 The American Phytopathological Society letter from the grower. This is adequate for common diseases caused by aggressive and obvious pathogens. However, many of the most difficult diseases to diagnose are a result of subtle interactions in the crop ecosystem that may involve pathogens, weather, soil and/or nutrition, and many other things. Crop management may have exacerbated the problem or caused it in the first place. These cases involve real detective work, where a field visit and an interview with those managing the crop is usually required to get to the bottom of the problem. Published works on plant disease diagnosis all emphasize the importance of good information from both the grower/ manager and the crop environment $(4,5,14$, 19,23,24).

For the grower, a diagnosis is only part of the solution. "What is it?" is followed by "What do I do about it?" A diagnosis has no practical value unless it includes a recommendation for how to deal with the problem (23). Perhaps also should be added, "How important is it?" An indication of the risk posed to the crop by a detected pathogen should also be part of the overall problem assessment (8).

Experience is crucial in learning the art of disease diagnosis. "On-the-job" training is one of the most effective ways to learn this process. In some parts of the world, plant clinics offer training both in the laboratory and in the field (25). Given that hands-on extension pathology (and hence a source of training) in western Englishspeaking countries has declined in recent years, it is more important than ever that students be introduced to this process as part of their formal training. Techniques of isolation and pathogen identification are easy to teach in a standard university course, but teaching the skills of the field diagnosis are a lot more difficult, especially in departments without an active extension program and with stretched teaching resources. Fortunately, instructional technology can assist in this task, as it can with teaching plant pathology generally (18).

This paper describes the authors' experience in utilizing instructional technology to develop problem-based approaches to training students in plant disease diagnosis. The first of these is a scenario-based "game" approach where students are expected to analyze a problem, the second involves students constructing scenarios in order to better understand the diagnostic processes involved, and the third looks at using software as a "diagnostic guide and record keeper" while trying to solve a real diagnostic problem both in the field and in the laboratory.

\section{The Diagnostic Process and Its Role in Teaching}

Much work has been done on the cognitive processes that take place during diagnosis for human and animal diseases (3,9$11,13,15)$. The same processes are likely to be used during the diagnosis of plant diseases. Being aware of these cognitive steps is important both in using and in developing diagnostic teaching scenarios for students to explore. Realistic scenarios are required, and such scenarios should allow the students to undertake this diagnostic reasoning. Students, at the level of knowledge being taught, should have the opportunity to form and explore hypotheses on the basis of the initial scenario information. This means the problems should not be too easy so that they are diagnosed immediately, nor should they be so difficult and beyond the students' subject knowledge (or their ability to find that knowledge) that they are unable to form any meaningful hypotheses at all.

There is a school of thought in medical education that this problem-solving clini- 
cal diagnostic process be introduced early into the curriculum and that students will learn the basic "facts" when requiring them in a problem-solving situation. There are problems with this approach. Supported by research, Magnani argues that leaving students to merely gather experiential knowledge runs the risk of building a huge situation-knowledge database that is not connected with theoretical, general knowledge of the discipline (11). In other words, there is a lack of scientific background. It is better to leave clinical diagnosis exercises until later in the curriculum, because students perform better in a diagnostic exercise if they are already armed with much of the knowledge and principles of disease. This reinforces the way we have used these exercises; i.e., not with introductory plant pathology students, but rather with those who already have a grounding in the discipline. Notwithstanding this, there is scope for these approaches to be used in a more general plant or biology-related context and at lower academic levels simply by selecting problems within the capacity of these students to solve, given their existing base knowledge and skills. For example, approach 1, discussed below, can easily be tailored to the level of students' abilities, both through the selection of the scenario to be worked through and the amount of interpretation done for the student within the scenario text.

\section{Approach 1: Presenting students with a problem-based scenario to solve}

(a) The student exercise. In this approach, students are presented with a real or artificial scenario and are asked to make an assessment of the problem and give recommendations as to a treatment. Special software is available (DIAGNOSIS for CROP PROBLEMS) which allows a series of tasks and observations to be carried out with the students shown (in pictures, text, and/or video) the results of their activities (Fig. 1). The significance of these observations must be interpreted by the student. The program tracks their progress through the scenario and can provide both general and specific feedback on the problem and the significance of students' choices. At the end of the exercise, the student provides a diagnosis, a justification, and a recommendation, which is marked by the teacher.

The components of DIAGNOSIS for CROP PROBLEMS discussed in this paper are available free-of-charge at http//www.diagnosis.co.nz. The software, its various versions, and its use in the classroom have been described in other papers and will not be duplicated here (2022). It is the problem-based paradigm itself that we wish to emphasize in this paper, rather than the software. Specific packages such as DIAGNOSIS for CROP PROBLEMS assist in giving students an interactive diagnostic experience, but this approach is not tied only to software. In fact, software does not need to be used at all. The mechanisms by which the students tackle the problem can take many forms. It could be as simple as a class tutorial, where students are guided through the process by the teacher. Alternatively, they could be given the scenario in written form and asked to analyze it. A scenario could be presented using web pages, with hyperlinks leading to the results of tests and observations. Although more technically challenging for the author, scenarios could also be produced using authorware such as Macromedia Director (Macromedia Inc., San Francisco) and the like.

At Massey University, we use this goalbased scenario approach (17) mostly in a third-year undergraduate plant pathology/entomology course for our Bachelor of Science (plant protection) and Bachelor of Applied Science degrees. It is a practical course, which emphasizes crop manage-

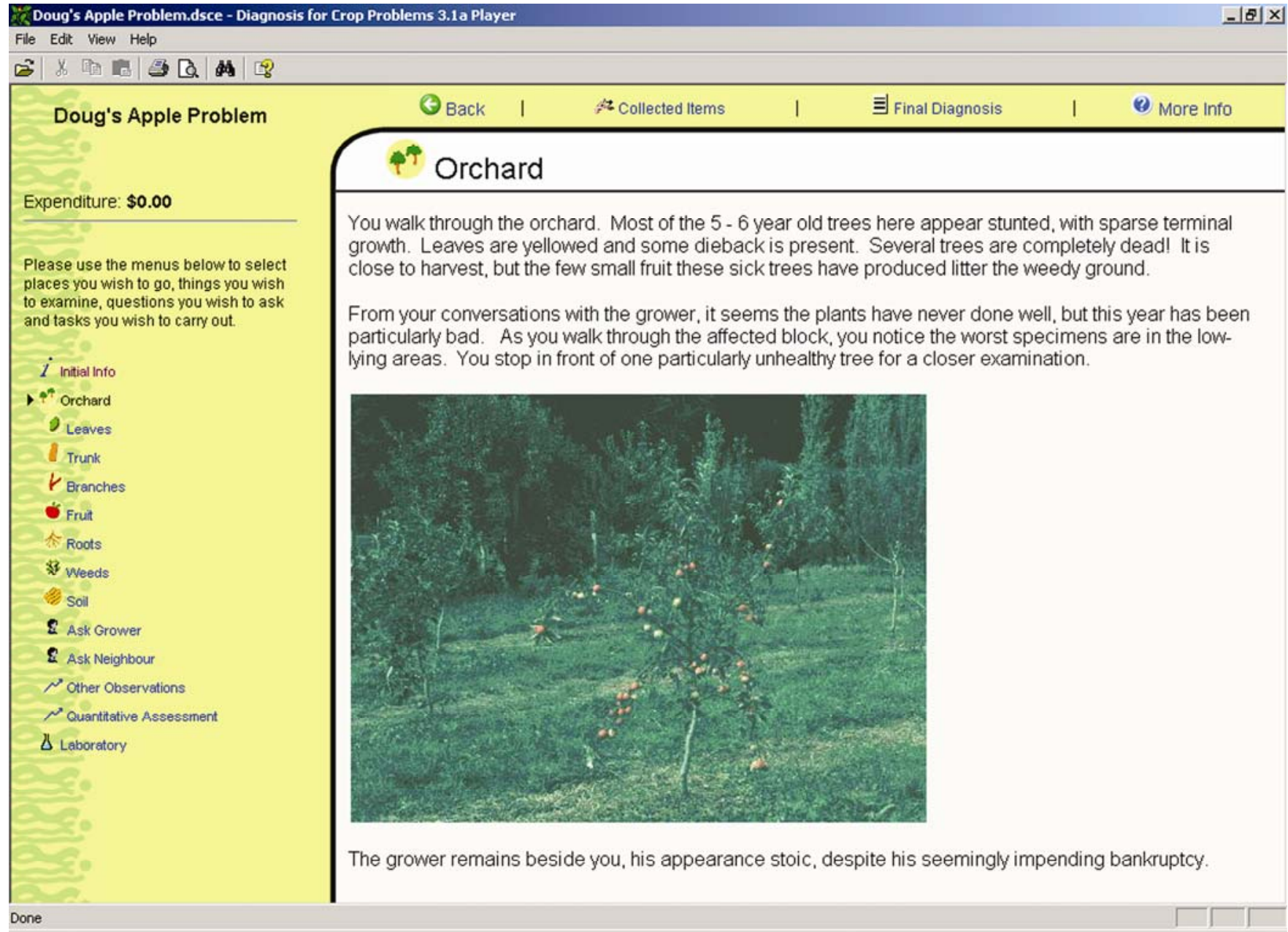

Fig. 1. The DIAGNOSIS for CROP PROBLEMS Player introducing a scenario. 
ment with regard to pathogens (and recently, also pests). The requirements of the course lend themselves to problem-based learning.

By the time these exercises are introduced, students have already completed a second-year course on the principles of plant protection and several months of coursework for their third-year course. Students begin with two 1-hour lectures on the process of disease diagnosis. Toward the end of the lecture series, they are "walked through" a scenario, after which they undertake the exercises on their own.

By continually monitoring student interaction and satisfaction, we have found that the exercises work best when students undertake them in pairs or small groups. This way they can "bounce" ideas off each other, working and communicating as a team. However, students are not forced to work in groups, and we give them the option of working alone.

Students usually complete two scenarios in the diagnosis section of the course, one reasonably straightforward and the other more complex. Prior to 2003, students were expected to complete a diagnostic session within a certain time period (normally 2 hours). In 2004, students were given the exercises on a CD-ROM and could work through them as many times as they liked over a period of several weeks before submitting their report. This was done as a trial prior to offering the course in a distance learning mode. Although subtracting the time pressure and allowing students to walk through the scenarios a number of times made the experience less realistic, it was decided that teaching objectives were still being fulfilled. The main goal was to teach the process and to give students exposure to diagnostic cases rather than subjecting them to a timelimited "test".

Table 1 shows student response to the exercises. These figures were taken from student surveys run over a number of years. Student surveys were always qualitative, as there were normally no more than 10 students in the class at any one time, which made obtaining statistically significant data difficult. Also, not all the same scenarios were used in different years, and the way the exercises were presented differed in 2004 as explained above. However, as responses tended to be fairly consistent even with these differences, the averages are presented here. They show a positive response to the exercises.

(b) Developing scenarios for use with students. Good learning requires good scenarios. Even though software such as DIAGNOSIS for CROP PROBLEMS can assist with converting a scenario to a "playable" electronic form, actually determining the scenario content and which actions and tests should be included (or left out), given the teaching objectives of the course and prior knowledge, is harder to ascertain. Scenarios require much planning. Essential activities that will allow the student to test the correct hypothesis are necessary, but enough scope also must be given for the exploration of alternative (incorrect) hypotheses.

Anecdotal evidence suggests that teachers tend to use pre-written scenarios either supplied with the DIAGNOSIS for CROP PROBLEMS or available from the software's website, and seldom write their own. Lack of diagnostic experience and time are issues, but even those who do have extensive experience tend to encapsulate their reasoning (1). It can be difficult to unpack this from their minds into scenarios suitable for a student to explore.

It was felt that scenario construction by plant pathology teachers could be improved and encouraged if somehow there was a formalized framework that scenario creators could work through. At first, a kind of software wizard that would step the tutor through the process was considered. However, it was decided that something more versatile was needed, which the scenario author could revisit repeatedly and which could also be used to document the process. In the end, it was decided to simply use a template presented in a stan- dard electronic document as a tool for this task.

The Scenario Development Template takes the form of a Microsoft Word document broken into various sections and containing a number of tables the user is required to fill in. Figure 2 shows the main information gathered. Working from top to bottom, the document steps the scenario author through building a diagnostic scenario. The introduction explains the process of diagnostic reasoning and underlines how important it is to allow students to formulate hypotheses from the objects, actions, and tests they may undertake. The scenario author then works through the three sections described sequentially, inserting his or her own scenario information. The template itself contains an example scenario for guidance, which the scenario author can paste over. Rows in the tables can be added or deleted by the scenario author as required.

The first part of this section asks scenario authors to essentially develop a fact sheet listing the problem, its signs and symptoms, and what may have caused the problem in the first place. Based on this, scenario authors are then well-placed to determine the possible hypotheses students may reach after a preliminary investigation of the problem. They then list these, along with the tasks students would definitely need to carry out in order to test each hypothesis, and the results of these tasks. The scenario author now has specified the essential objects, actions, and tests needed in the problem-based scenario under development. Finally, the scenario author lists tasks and observations that may add interest to the scenario and make it more lifelike, but are not essential for testing the hypotheses formulated above. This completes part one. The author then prints a hard copy of this section and uses it as a reference for filling in section two.

Having gathered together all the relevant information for the chosen scenario, authors must now list the actual objects, actions, and tests (from section 1) that will

Table 1. DIAGNOSIS for CROP PROBLEMS Assignment 2002-2004 student survey $(\mathrm{SA}=$ strongly agree, $\mathrm{A}=$ agree, $\mathrm{U}=$ undecided, $\mathrm{D}=\mathrm{dis}$ agree, $\mathrm{SD}=$ strongly disagree), sample size $=23$

\begin{tabular}{|c|c|c|c|c|c|c|}
\hline Questions & SA & A & $\mathbf{U}$ & D & SD & $P^{\mathbf{a}}$ \\
\hline I enjoyed these exercises. & 14 & 8 & 0 & 1 & 0 & $<0.00$ \\
\hline The interface was intuitive and easy to use. & 9 & 12 & 1 & 1 & 0 & $<0.00$ \\
\hline $\begin{array}{l}\text { These exercises helped me improve my knowledge of the } \\
\text { diagnostic process. }\end{array}$ & 11 & 11 & 0 & 1 & 0 & $<0.00$ \\
\hline $\begin{array}{l}\text { I would have learned more from just covering diagnostic } \\
\text { examples given in formal lectures rather than using the } \\
\text { software. }\end{array}$ & 1 & 0 & 4 & 10 & 8 & $<0.00$ \\
\hline $\begin{array}{l}\text { I would have learned more from just being given } \\
\text { diagnostic examples in written form to read about at home } \\
\text { rather than using the software. }\end{array}$ & 1 & 0 & 2 & 12 & 8 & $<0.00$ \\
\hline $\begin{array}{l}\text { I found the typed "creator's solution" feedback comments } \\
\text { on the returned script helpful. }\end{array}$ & 7 & 13 & 3 & 0 & 0 & $<0.00$ \\
\hline $\begin{array}{l}\text { I prefer to go through a scenario with one other, rather } \\
\text { than myself. }\end{array}$ & 4 & 7 & 9 & 2 & 0 & 0.04 \\
\hline
\end{tabular}

\footnotetext{
${ }^{a}$ Based on one-way chi-square.
} 
be available to a student when working through the scenario. To each of these listed items, a response must also be written. This is the response that will be seen by students when they initiate a test or action.

Also included is the cost of that action (if any), a list of multimedia objects (pictures, video, etc.) that will be needed to illustrate the scenario (and where they can be found), and whether or not this particu- lar task reveals a significant clue to the correct diagnosis. The latter information is used later to provide the raw material for a de-briefing/feedback entry in the Diagnosis Builder, but it also could be used for group work in face-to-face tutorials. The feedback students will receive and author analysis of the scenario is also written into tables at this step.

The template now contains a documented scenario that can be checked by the author and others. As all the information is present in the document, it becomes a simple task to cut and paste it into specialized delivery software such as DIAGNOSIS for CROP PROBLEMS, or use the information in a non-computer-based tutorial.

The electronic template, even though just a simple Word document, is a valuable aid to constructing and formulating problem-based scenarios. It does two important

\section{PART 1 - PLANNING THE SCENARIO}

\section{A. What went wrong and why?}

The Problem itself:

Its Signs and Symptoms:

Predisposing factors that may have helped it develop:

\section{B. Which hypotheses should students be allowed to explore?}

For each hypothesis which is likely to be formed from the initial observations...

(a) The justification for that hypothesis in the signs and symptoms

(b) Supporting evidence for this hypothesis which exists from other sources (management, crop history, sudden events, location, etc

(c) Field observations or tasks (and their expected results) which will confirm/disprove the hypothesis

(d) Laboratory procedures required (and their expected results) to confirm/disprove the hypothesis

\section{What other tasks/test/observations should the students be allowed to make for the sake of completeness, even though in} this particular case, they will offer nothing toward solving the problem?

For each task

(a) Description of the task and the results

(b) Reason for including it

\section{PART 2 - CONSTRUCTING THE TASKS AND OBSERVATIONS}

\section{The initial observation}

(a) Description of what students will see when entering the scenario:

(b) Significance of observations to the real cause of the problems:

(c ) Details of any multimedia material which will be used (images, video etc.)

(d) Cost (if any):

(e) Help in interpretation which may be given to the student.

2. The allowable objects and tasks (e.g. examine roots, cut into fruit, isolate pathogens from fruit, check nutrient levels etc.)

For each task/object both in the field and laboratory (as determined in Part 1, B. (c) and (d)).

(a) Observation(s) or results

(b) Significance of these to the real cause of the problems:

(c) Details of any multimedia material which will be used (images, video etc.)

(d) Cost (if any):

(e) Help in interpretation which may be given to the student.

\section{The debriefing.}

(a) The solution and observations which strengthened/confirmed this hypothesis

(b) The diagnostic pathway that an experienced diagnostician would take (optimal route)

(c) The recommended action(s) to manage the problem

\section{PART 3 - GETTING THE SCENARIO CONTENT INTO A FORMAT WHERE IS CAN BE PRESENTED TO STUDENTS (e.g. Loading it into DIAGNOSIS for CROP PROBLEMS, linked webpages, paper-based description etc.)}

Fig. 2. Steps for developing a diagnostic scenario for a student exercise, showing the information required for the scenario development template. 
things. First, it forces a process and some rigor on scenario development. Second, it can also be stored as a permanent record of the development process in an easy-toview and portable form.

The template is available for any pathology teachers to use without cost on the DIAGNOSIS for CROP PROBLEMS Website.

\section{Approach 2: Having students develop their own scenarios}

Approach 1 has a limitation in that scenarios need to be available. Not only are they time-consuming to create, but there needs to be a number of them, as once the solution to a scenario is known among a cohort of students, this can become public knowledge among the student body. Scenarios need to be rotated over a number of years.

Rather than simulating a diagnostic episode and getting students to analyze a problem, some teachers, including the second author of this paper, have used DIAGNOSIS for CROP PROBLEMS primarily as a tool to allow students to construct their own scenarios. The preposition is that in thinking about the diagnostic process and determining what common diagnostic activities should reveal for a plant or crop problem, students actively engage with knowledge and thereby see the relevance of it. As with approach 1, it is a constructivist mode of learning (2).

At the University of Queensland, thirdyear students in Plant Protection utilize the "Builder" mode of a freeware student version of DIAGNOSIS for CROP PROBLEMS to author their own original plant problem scenarios. Students are required to author a scenario that will stand the test of "professional" scrutiny. In doing this, they find themselves being actively engaged in the diagnostic process. There is also a requirement for them to pay extra attention to detail, presentation, and logic of approach to author scenarios of appropriate quality.

Working in pairs, students select a problem that is difficult to diagnose, with the objective of writing a scenario that can be used by other students. The use of teams encourages collaborative support, adding learning value to the exercise while improving the likelihood of a successful outcome.

(a) Familiarization with diagnosis player. Students begin this process by performing diagnostic analyses on real plant material in a laboratory class. Normally, six or more unknown diseased plant specimens that have been freshly collected from field crops or local nurseries are presented to the class. Students are guided through the logical approach and process of diagnosis with one or two specimens, using appropriate tools and reference materials. The remaining specimens are diagnosed by students working in small teams, and the process is reviewed collectively by the whole class upon completion of the session.

Familiarization with the software is achieved by exposing the student group to the "Player" mode of DIAGNOSIS for CROP PROBLEMS. Using a computer laboratory, the students are given a guided tour of their first scenarios, then left to work through five or six remaining scenarios to become familiar with the logic of the computer-based diagnostic process and to become confident with operation of the software.

(b) Scenario creation. To initiate the process of designing scenarios, a tutorial is conducted in the computer laboratory. Students contribute to building a flow chart describing the diagnosis of a known "case" (e.g., Fusarium wilt in tomato), which is developed on a white board. This session introduces the concept of scripting a scenario, and demonstrates how to access relevant information and images using online resources. Students are also introduced to the idea of providing redundant clues and procedures (red herrings), which allows the exploration of possible but incorrect hypotheses, something that often occurs in the course of conducting an actual diagnostic analysis. In short, the tutorial follows the same pathway as the scenario development template discussed previously.

Particular attention is paid to students creating a believable scenario. Not only is attention to scientific and logical detail required, but also the creation of an appropriate context for the problem, including the role of the person who will investigate the scenario (the crop consultant) and the development of the character for the client (farmer). Students are encouraged to use the full multimedia capabilities of the software to build a scenario that is factual, believable, and entertaining.

To facilitate the preparation of the assignment, students are given access to the software for installation on their own computers, and it is also available for use in the computer laboratory.

(c) Assessment. Upon completion of their scenarios, the student teams submit a computer file for assessment. The scenario files are evaluated using the DIAGNOSIS for CROP PROBLEMS "Player". Table 2 shows the criteria used to assess the student-prepared scenarios. Students are made aware of these criteria in advance.

(d) Results and discussion. The close proximity of commercial horticulture to the University of Queensland Gatton campus allows ready access to material demonstrating a wide range of plant health issues. Along with using DIAGNOSIS for CROP PROBLEMS in the "Player" mode to teach the art and science of diagnostic procedure, the use of the "Builder" mode has reinforced the elements from which a diagnostic case is constructed. This approach has been used to deconstruct the diagnostic process by using the very tool used by experts to build DIAGNOSIS for CROP PROBLEMS scenarios. Other teachers of plant pathology have also independently adopted this approach (18).

In some cases, students have developed scenarios around cases they themselves have experienced while monitoring crops for local farmers. In the latter cases, having personal ownership over a scenario certainly enhances its value to those students.

Using the Builder to create scenarios requires them to thoroughly research the plant health problem they have chosen, rather than simply solving it, as required in the Player. Not only are they required to deal with the technical content of the scenario, but they also engage in story line development and need to master the multimedia requirements for this assignment. The very nature of this exercise allows students to demonstrate original and creative thought. This is expressed by the choice of scenario (unique problem selection), clever and often humorous scripting

Table 2. Criteria used to assess student scenarios, constructed in the DIAGNOSIS FOR CROP PROBLEMS Builder

\begin{tabular}{|c|c|}
\hline Criterion & Details \\
\hline $\begin{array}{l}\text { Actions, objects, and } \\
\text { procedures available }\end{array}$ & $\begin{array}{l}\text { Are the field investigation methods appropriate and sufficiently } \\
\text { thorough? }\end{array}$ \\
\hline $\begin{array}{l}\text { Historical/background } \\
\text { information }\end{array}$ & $\begin{array}{l}\text { Does the background information supplied adequately relate to the case } \\
\text { presented and is there sufficient richness of information? }\end{array}$ \\
\hline The laboratory & $\begin{array}{l}\text { Are the laboratory investigations appropriate for the samples collected } \\
\text { and do they demonstrate sufficient rigor? }\end{array}$ \\
\hline Final diagnosis & $\begin{array}{l}\text { Is the final diagnosis one which can be realistically concluded given the } \\
\text { information set provided in this scenario? Has an appropriate optimal } \\
\text { route for the diagnostic pathway been identified? }\end{array}$ \\
\hline Recommendations & $\begin{array}{l}\text { Are the recommendations appropriate and of sufficient quality for this } \\
\text { problem in the context within which it is set? }\end{array}$ \\
\hline Technical content & $\begin{array}{l}\text { Would the overall technical content for this scenario be appropriate and } \\
\text { believable in a plant health diagnostic situation? }\end{array}$ \\
\hline Originality and creativity & $\begin{array}{l}\text { Does this scenario demonstrate evidence of original and creative use of } \\
\text { multimedia skills, development of characters and situation context? }\end{array}$ \\
\hline Visual content & $\begin{array}{l}\text { Are the images used and the overall appearance of this scenario } \\
\text { appropriate for its context and content? }\end{array}$ \\
\hline
\end{tabular}


of characters and story lines, and interesting use of multimedia (use of original images, voice recordings, and video footage). Many students appreciate the opportunity to demonstrate their creativity in a format atypical for undergraduate programs in agriculture. Some of the better scenarios authored by students have been further developed and placed in the public domain.

\section{Approach 3: Using an electronic form as a guide and a recording/reflection device to document a real diagnosis}

A limitation to approach 2 is that it sometimes results in students "assembling" a diagnostic scenario that may have an appropriate and logical structure but lacks technical rigor. A lack of relevant laboratory practice in diagnostic methods and procedures often leaves students guessing at which techniques are available or even appropriate to the type of case they have chosen.

It was therefore decided that an even better approach to teaching students about the diagnostic process would be to ask them to take on a real plant disease case for a commercial client. The background to this case would be researched by the student dealing directly with the client and the problem worked through in the laboratory drawing upon advice where necessary from the academic.

An electronic template was developed for this process. This was presented in a derivative of the DIAGNOSIS for CROP PROBLEMS (version 3) Builder, called CHALLENGE FRAP (form for recording the analysis of problems). The FRAP diagnostic template contained suggested actions within a diagnostic framework and explained their significance. This explanatory text connected with each suggested action could be replaced with students' own observations as they undertook the real-world tasks. Actions, locations, and objects could be deleted and added at will, depending on what was actually done. The form could be reloaded, saved, and shared, enabling the supervising academic to add his or her own comments at different phases of the exercise (Fig. 3). Eventually, it contained a full record of the student's diagnostic experience.

This template served to guide the student through the logical approach to addressing, investigating, and solving this problem (Fig. 4) while also providing a means for recording the pathway taken by the student and documenting any supporting information (reference material) and evidence (photographs and information) collected during this process. The template also provided a discussion/feedback tool to allow communication between the student and academic to assist with development of the case through constructive feedback and reflective comment, and ultimately served as a mechanism for assessment of the students' work

(a) Method. In 2004, 10 students enrolled in Plant Protection at the University of Queensland were asked to select a plant disease case from 14 problems submitted for consideration by a range of horticultural clients from southeast Queensland. Each student was provided with brief de-

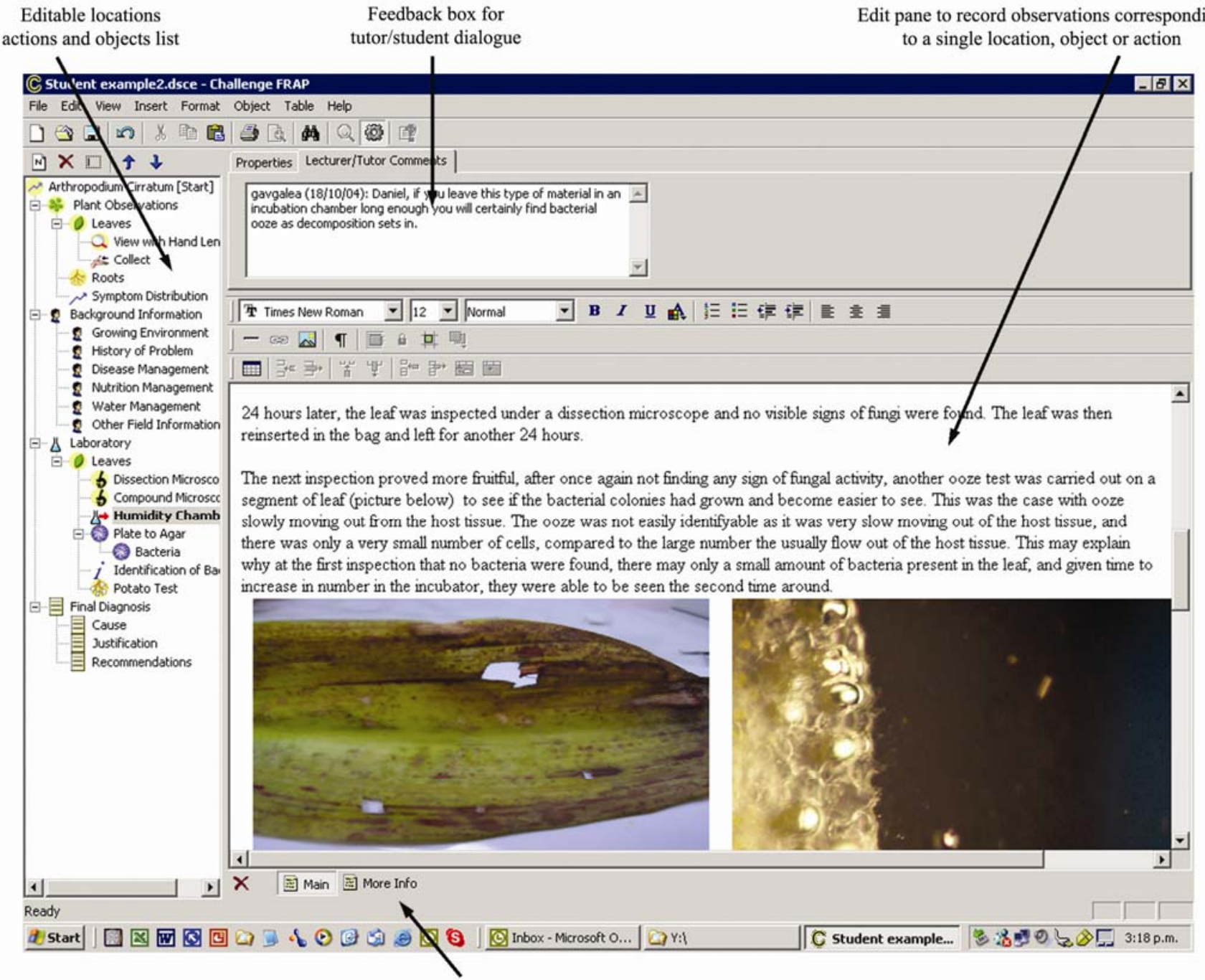

Opens new pane, giving optional tutor-supplied guidelines for this kind of activity

Fig. 3. Screen-shot showing part of a student's FRAP diagnostic assignment. 
tails on their selected case along with the contact details of their client. Students were also provided with the case template (as a FRAP file) and had been previously exposed to some laboratory diagnostic cases. They had also been familiarized with Diagnosis Player and a selection of scenarios, and exposed to the diagnostic process as outlined in Figure 4. The elements identified in this flowchart and their logical inter-relationship are essential to the completion of a diagnostic case.

Students were given access to all laboratory and glasshouse facilities required to carry out their individual tasks and were able to consult with the academic, and where necessary, receive guidance and relevant training on techniques to assist with their case. Where required, access to digital photography and photomicrography was also provided.

(b) Submission of draft. Students were invited to submit a draft of their FRAP file (now their assignment) to allow for constructive feedback and guidance by the academic. Students were able to use the discussion/feedback box available for each screen to raise questions or concerns about individual components of their diagnostic case. Constructive feedback on these and other issues could then be given by the academic to guide the students toward a more polished outcome.

(c) Final submission. After consideration of the feedback from the academic, and if required, further investigation of the problem, students were able to submit a final version of their diagnostic case FRAP file. This final submission was then assessed by the academic using the assessment criteria shown in Table 3.

(d) Results and discussion. Student attitudes toward this learning approach were investigated through the use of two questionnaires. The first, containing nine open-

Table 3. Assessment criteria for diagnostic assignments, as reported in their CHALLENGE FRAP file

\begin{tabular}{ll}
\hline Criterion & Details \\
\hline Introduction of problem & $\begin{array}{l}\text { The plant problem and the context within which it occurs should be } \\
\text { clearly introduced by the student. } \\
\text { Evidence of ability to consult with client should be demonstrated by } \\
\text { the relevance and quality of information sought by the student. } \\
\text { Appropriate information sources to support this case should be } \\
\text { accessed and evidence of this presented within the assignment. } \\
\text { Accessing information }\end{array}$ \\
$\begin{array}{l}\text { Laboratory (skills) perform- } \\
\text { ance }\end{array}$ & $\begin{array}{l}\text { A methodical approach to the laboratory phase of this investigation } \\
\text { should be demonstrated, along with the correct choice and use of } \\
\text { laboratory techniques. }\end{array}$ \\
Diagnostic reasoning & $\begin{array}{l}\text { The conclusions drawn from the diagnostic investigation should be } \\
\text { justified and be relevant and appropriate to the information collected } \\
\text { by the student. } \\
\text { The management program must be realistic and relevant both to the } \\
\text { production system, the crop being grown and the problem(s) to be } \\
\text { managed. } \\
\text { Validity of recommendations } \\
\text { The student's dedication to the project through the quality of } \\
\text { interaction with the client and lecturer and effort in the laboratory } \\
\text { should be demonstrated. } \\
\text { The student should provide evidence of feedback on the case to the } \\
\text { client. }\end{array}$ \\
\hline Feedback to client &
\end{tabular}

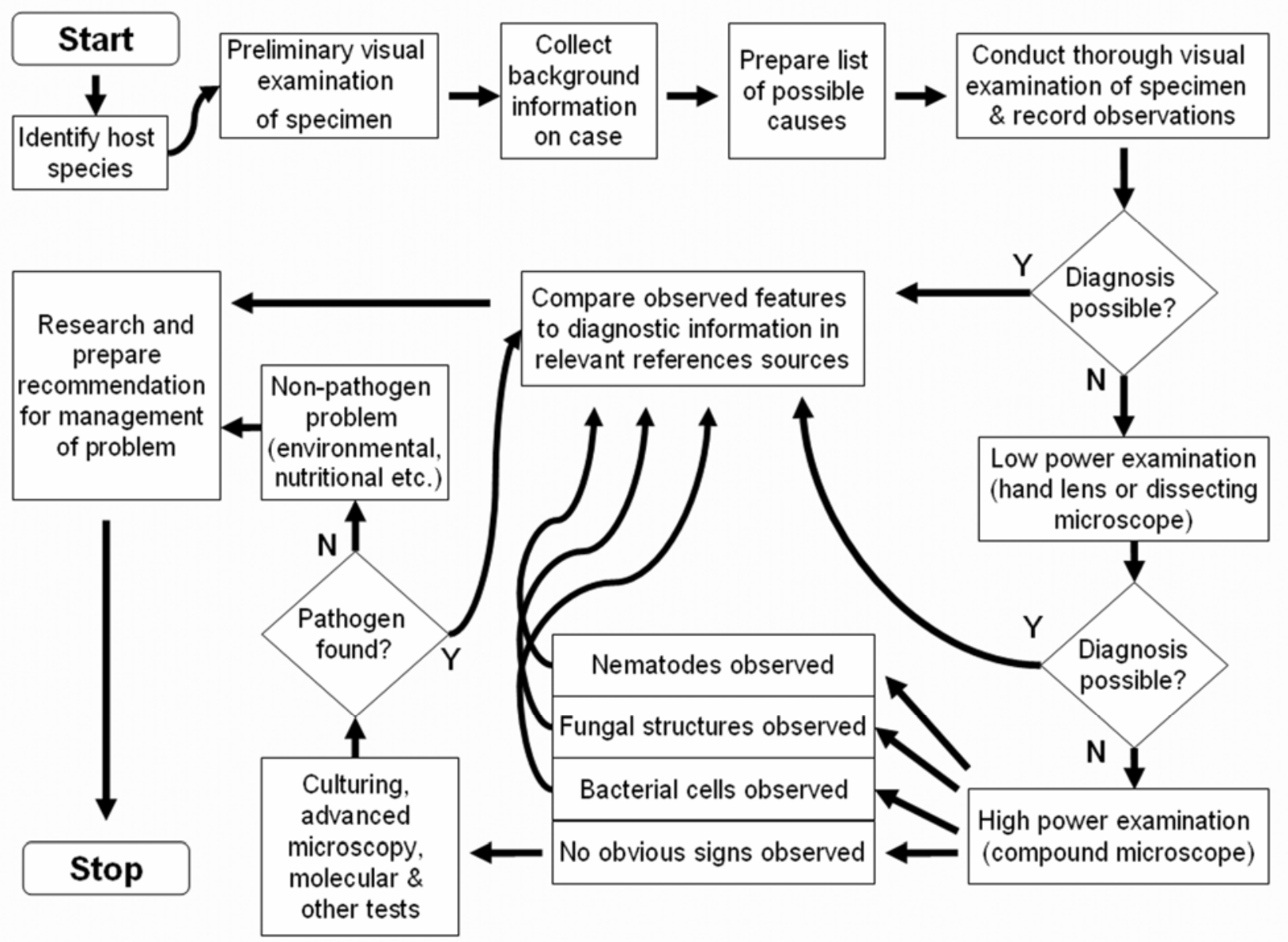

Fig. 4. Flowchart describing the logical approach to the diagnosis of a plant disease problem. 
ended questions, examined student attitudes toward this exercise, its conduct, and resource issues. This first evaluation was performed by the students upon submission of the draft diagnostic case FRAP template, and it provided valuable feedback as to student progress through the exercise. Comments were mostly positive.

The second, which was a more searching examination of value of the learning exercise, measured the success of the template as a mechanism for case development and the overall benefit of this case study approach. This questionnaire consisted of 26 attitude questions and seven openended questions. The opportunity for students to provide constructive feedback on the mechanisms used in this exercise was also given. This questionnaire was completed by nine of the 10 students upon submission of the case template. For the sake of brevity, only the attitude questions from the final questionnaire are reported here (Table 4).

Students found that this learning exercise was stimulating and relevant. They appreciated working on their own case in their own timeframe and doing so for a real client. The progressive feedback given to them was found to be useful, and it was felt that this style of self-directed project learning was better and more engaging than working through cases under more conventional (lab, lecture, or readings) approach.

The FRAP template was easy to use and supported students by providing not only a logical structure and a methodical approach to the investigation, but also a useful, flexi-

Table 4. Final survey of student opinion on their field/lab diagnostic scenario exercise using the CHALLENGE FRAP program with diagnostic template (SA $=$ strongly agree, $\mathrm{A}=$ agree, $\mathrm{U}=$ undecided, $\mathrm{D}=$ disagree, $\mathrm{SD}=$ strongly disagree), sample size $=9$

\begin{tabular}{|c|c|c|c|c|c|c|}
\hline Questions & SA & $\mathbf{A}$ & $\mathbf{U}$ & D & SD & $P^{\mathbf{a}}$ \\
\hline \multicolumn{7}{|l|}{ (a) Learning context } \\
\hline $\begin{array}{l}\text { I preferred having my own plant disease case to work on, rather } \\
\text { than working through a case with other students. }\end{array}$ & 6 & 2 & 1 & 0 & 0 & 0.01 \\
\hline $\begin{array}{l}\text { Knowing that this was a problem of commercial significance } \\
\text { made this project more relevant to me. }\end{array}$ & 6 & 2 & 1 & 0 & 0 & 0.01 \\
\hline $\begin{array}{l}\text { Having a real client to work for improved the value of this } \\
\text { project for me. }\end{array}$ & 5 & 2 & 2 & 0 & 0 & 0.05 \\
\hline I preferred working on this project in my own timeframe. & 5 & 3 & 1 & 0 & 0 & 0.03 \\
\hline $\begin{array}{l}\text { The formal feedback received before the project was complete } \\
\text { and useful. }\end{array}$ & 6 & 3 & 0 & 0 & 0 & $<0.00$ \\
\hline $\begin{array}{l}\text { I think I would learn more from just working through a } \\
\text { historical case, where I had to interpret given observations and } \\
\text { lab results in order to reach a diagnosis, (along with being } \\
\text { exposed to diagnostic procedures in lab classes), rather than } \\
\text { undertaking this project. }\end{array}$ & 0 & 0 & 1 & 7 & 1 & $<0.00$ \\
\hline $\begin{array}{l}\text { I think I would learn more from just covering diagnostic cases in } \\
\text { lectures and being exposed to diagnostic procedures in lab } \\
\text { classes, rather than undertaking this project. }\end{array}$ & 0 & 0 & 1 & 1 & 7 & $<0.00$ \\
\hline $\begin{array}{l}\text { I think I would learn more from just being given diagnostic } \\
\text { cases to read about, rather than undertaking this project. }\end{array}$ & 0 & 0 & 0 & 1 & 8 & $<0.00$ \\
\hline \multicolumn{7}{|l|}{ (b) The FRAP template } \\
\hline The template provided a logical structure to this project. & 6 & 3 & 0 & 0 & 0 & $<0.00$ \\
\hline $\begin{array}{l}\text { The template provided a useful way to record my observations } \\
\text { and thoughts during the project. }\end{array}$ & 6 & 1 & 2 & 0 & 0 & 0.01 \\
\hline $\begin{array}{l}\text { The structure within the template served as a model of common } \\
\text { tasks and procedures which assisted me with my investigation. }\end{array}$ & 5 & 3 & 1 & 0 & 0 & 0.03 \\
\hline $\begin{array}{l}\text { The template assisted me (helped me focus) when seeking } \\
\text { information from the client. }\end{array}$ & 4 & 4 & 1 & 0 & 0 & 0.05 \\
\hline $\begin{array}{l}\text { The comments and guidelines initially provided within the tem- } \\
\text { plate were useful to me. }\end{array}$ & 5 & 3 & 1 & 0 & 0 & 0.03 \\
\hline The feedback/discussion feature was useful to me. & 4 & 4 & 1 & 0 & 0 & 0.05 \\
\hline $\begin{array}{l}\text { The multimedia capabilities allowed me to better document the } \\
\text { problem. }\end{array}$ & 3 & 5 & 1 & 0 & 0 & 0.03 \\
\hline $\begin{array}{l}\text { The fact that the template structure could be altered to reflect my } \\
\text { own investigation was a good feature. }\end{array}$ & 8 & 1 & 0 & 0 & 0 & $<0.00$ \\
\hline The template was easy to use. & 6 & 3 & 0 & 0 & 0 & $<0.00$ \\
\hline \multicolumn{7}{|l|}{ (c) The laboratory investigation } \\
\hline I was strongly engaged by the laboratory phase of the diagnosis. & 4 & 5 & 0 & 0 & 0 & 0.01 \\
\hline I learned new skills conducting this phase of the investigation. & 8 & 1 & 0 & 0 & 0 & $<0.00$ \\
\hline $\begin{array}{l}\text { My level of understanding of the diagnostic procedure was } \\
\text { improved as a result of this phase of the project. }\end{array}$ & 8 & 1 & 0 & 0 & 0 & $<0.00$ \\
\hline \multicolumn{7}{|l|}{ (d) Learning benefits } \\
\hline I have developed useful skills as a result of this project. & 5 & 4 & 0 & 0 & 0 & 0.01 \\
\hline $\begin{array}{l}\text { I found this problem-based learning approach to be more } \\
\text { interesting than conventional content delivery. }\end{array}$ & 7 & 2 & 0 & 0 & 0 & $<0.00$ \\
\hline $\begin{array}{l}\text { The project helped improve my knowledge of plant protection } \\
\text { generally. }\end{array}$ & 4 & 5 & 0 & 0 & 0 & 0.01 \\
\hline The project reinforced theory learned elsewhere in this course. & 3 & 6 & 0 & 0 & 0 & $<0.00$ \\
\hline The project served to integrate knowledge with skills. & 5 & 4 & 0 & 0 & 0 & 0.01 \\
\hline I enjoyed this project. & 6 & 3 & 0 & 0 & 0 & $<0.00$ \\
\hline
\end{tabular}

a Based on one-way chi-square. 
ble, and customizable means of documenting information, observations, and thoughts generated during this process. The discussion/feedback component supported progressive development of the student case.

The laboratory phase of the investigation was found to be highly engaging to the students. As a result, new skills and an increased knowledge of the diagnostic procedure were acquired.

Learning benefits to students as a result of this approach to diagnostic assignment included the development of useful skills and improved knowledge of plant protection. Students found this approach more interesting and enjoyable than conventional content delivery, and relevant as it integrated skills with knowledge and reinforced theory learned elsewhere.

There appears to be much value in this approach for developing of plant disease diagnostic skills in students. It was clearly evident from the case study templates submitted by participants that they succeeded in embracing the philosophy and approach to conducting diagnostic evaluations of plants with diseases that were previously unknown to them. In being required to conduct a diagnosis for a real client, reality was brought one step closer for students. The FRAP template not only captured a record of their work, but also provided guidance to the diagnostic procedure and allowed teacher feedback.

The CHALLENGE FRAP program and diagnostic template are available free of charge from the DIAGNOSIS for CROP PROBLEMS Website.

\section{Summary}

The art of plant disease diagnosis goes beyond identification or confirmation of a suspected pathogen. The ability to diagnose a plant condition from a host of possibilities and provide a recommendation is critical for plant pathologists engaged in extension work. Changes in the way plant pathology is taught and funded in Englishspeaking western countries suggest there may be a shortage of extension pathologists with these field diagnostic skills in the future. It is important, therefore, that students pursuing a career in plant pathology or plant protection are exposed to diagnostic procedures and processes just as medical practitioners are.

In this area, experience is the best teacher. However, despite the obvious constraints, students can be exposed to this problem-solving process within a formal classroom setting, giving them an experience that goes beyond laboratory isolation or identification of pathogens.
This paper has reported three examples of teaching practice that assist with this training, namely, presenting students with a problem scenario and asking them to solve it, getting students to construct their own problem scenarios, and using an electronic form as a guide, recording, and feedback tool during a real-life diagnostic exercise. The authors and other plant pathology teachers have used approaches 1 and 2 for many years, with positive results. Approach 3 requires student fieldwork, which may be difficult to organize in many institutions. However, a combination of a real diagnostic experience plus the use of an electronic framework, feedback, and recording tool makes for a seminal student experience.

The examples as reported above are used in undergraduate courses within specific plant protection papers. It is appreciated that many plant pathology students do not learn the specifics of the discipline until their postgraduate years, after having completed a more general undergraduate course in the applied biological sciences. However, these training approaches should be equally applicable to postgraduate students of this type.

All the training approaches above use software to assist delivery and management of the student experience. However useful this technology is, the problemsolving paradigm and sound teaching pedagogy are most influential in training students in the art and science of plant disease diagnosis.

\section{ACKNOWLEDGMENTS}

We thank other plant pathology teachers who have supported these approaches over the years. A special thanks to Professor Geoff Norton, University of Queensland, for his support for this problem-solving paradigm and the instructional technology to deliver it, along with constructive criticism during the preparation of this paper. Thanks also to Dr. Peter Long, Massey University, for checking this manuscript for errors.

\section{LITERATURE CITED}

1. Boshuizen, P. A., and Schmidt, H. G. 1992. On the role of biomedical knowledge in clinical reasoning by experts, intermediates and novices. Cognitive Sci. 16:153-184.

2. Bruner, J. 1990. Acts of Meaning. Harvard University Press, Cambridge, MA.

3. Elstein, A. S., and Schwarz, A. 2002. Clinical problem-solving and diagnostic decision making. Selective review of the cognitive literature. BMJ Volume 321:729-732

4. Grogan, R. G. 1981. The science and art of plant-disease diagnosis. Annu. Rev. Phytopathol. 19:333-351.

5. Grogan, R. G. 1987. The relation of the art and science of plant pathology for disease control. Annu. Rev. Phytopathol. 25:1-8.

6. Hardwick, N. V. 1998. Whither or wither extension plant pathology? Plant Pathol.
47:379-393.

7. Holmes, G. J., Brown, E. A., and Ruhl, G. 2000. What's a picture worth? The use of modern telecommunications in diagnosing plant diseases. Plant Dis. 84:1256-1265.

8. Hughes, G., McRoberts, N., and Burnett, C. 1999. Decision-making and diagnosis in disease management. Plant Pathol. 48:147-153.

9. Josephson, J. R., and Josephson, S. G. 1996 Abductive Inference. Computation, philosophy, technology. Cambridge University Press, New York.

10. Kassier, J. P. 1989. Diagnostic reasoning. Ann. Internal Med. 110:893-900.

11. Magnani, L. 1997. Basic science reasoning and clinical reasoning intertwined: Epistemological analysis and consequences for medical education. Adv. Health Sci. Edu. 2:115-130.

12. Miller, J., and Moran, J. 1997. An evaluation of the disease diagnostic capabilities of Australian plant industries. Final Rep. Rural Industries Res. Devel. Corp. Project No. DAV $107 \mathrm{~A}$.

13. Pollock, R. V. H. 1985. Anatomy of a diagnosis. Compend. Continuing Edu. Practicing Veterinarian 7:621-628.

14. Putnam, M. L. 1995. Evaluation of selected methods of plant-disease diagnosis. Crop Prot. 14:517-525.

15. Ramoni, M., Stefanelli, M., Magnani, L., and Barosi, G. 1992. An epistemological framework for medical knowledge based systems. IEEE Transact. Systems, Man, Cybernetics 22:1-14.

16. Schaad, N. W., Frederick, R. D., Shaw, J., Schneider, W. L., Hickson, R., Petrillo, M. D., and Luster, D. G. 2003. Advances in molecular-based diagnostics in meeting crop biosecurity and phytosanitary issues. Annu. Rev. Phytopathol. 41:305-324.

17. Schank, R. A., Fano, A., Bell, B., and Jona, M. 1993. The design of goal-based scenarios. J. Learning Sci. 3:305-345.

18. Schumann, G. L. 2003. Innovations in teaching plant pathology. Annu. Rev. Phytopathol. 41:377-398.

19. Shurtleff, M. C., and Averre, A. W. 1997. The Plant Diseases Clinic and Field Diagnosis of Abiotic Diseases. American Phytopathological Society, St Paul, MN.

20. Stewart T. M. 1992. DIAGNOSIS, a microcomputer-based teaching aid. Plant Dis. 76:644-647.

21. Stewart, T. M. 2004. Teaching the art and science of plant disease diagnosis: Training students with DIAGNOSIS for CROP PROBLEMS. The Plant Health Instructor. DOI: 10.1094/PHI-T-2004-0426-01.

22. Stewart, T. M., Blackshaw, B. P., Duncan, S., Dale, M. L., Zalucki, M. P., and Norton, G. A. 1995. Diagnosis: a novel, multimedia, computer-based approach to training crop protection practitioners. Crop Prot. 14:241-246.

23. Stowell, L. J., and Gelernter, W. D. 2001 Diagnosis of turfgrass diseases. Annu. Rev. Phytopathol. 39:135-155.

24. Streets, R. B. 1971. The diagnosis of plant diseases. A field and laboratory manual emphasizing the most practical methods for rapid identification. University of Arizona Press, Tucson.

25. Usher, R., Ben-Ze'ev, I. S., and Black, R. 1996. The role of plant clinics in plant disease diagnosis and education in developing countries. Annu. Rev. Phytopathol. 34:51-66. 